\section{Worldwide news}

\section{and comment}

\section{JAPAN: 2020 OLYMPICS GAMES MIXED SMOKE FREE LEGACY}

Japan's forthcoming hosting of the 2020 Tokyo Olympics has presented an opportunity to raise public awareness and strengthen laws to protect the public from secondhand smoke (SHS), due in part to the International Olympic Committee's tobacco-free policy. As a result of tobacco industry interference, SHS protection in Japan is weak by international standards, so there has also been concern about the possible reaction of international visitors.

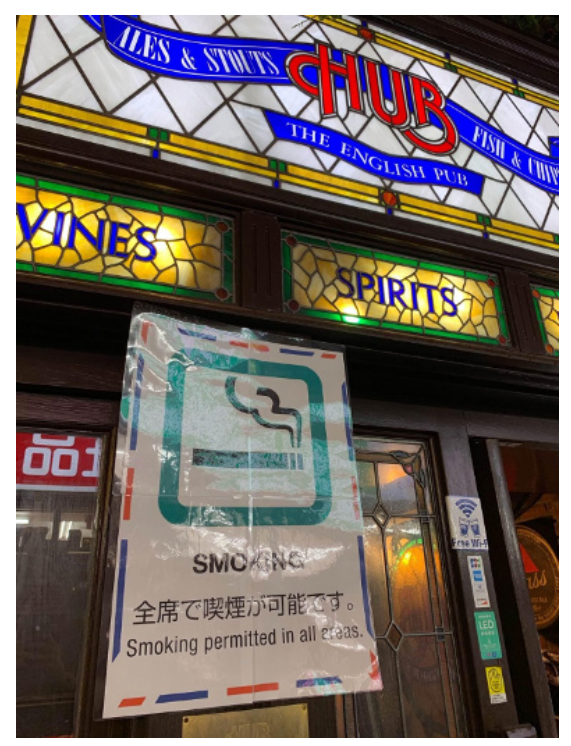

A popular chain pub in Japan proclaims itself'all smoking' prior to the ban on April 1, 2020.Photo by Christophe Arts

In 2017, Japan still had only voluntary restrictions on smoking in indoor public places nationally. There were proposals for mandatory SHS protection, both nationally and in Tokyo. However, these were far below the standards of WHO FCTC Article 8, as indoor smoking would still be permitted in small restaurants and bars. Nonetheless, even these inadequate proposals were met with fierce opposition from the tobacco industry. In 2018, a weakened proposal became the revised Health Promotion Law (HPL). Based

All articles written by Marita Hefler unless otherwise attributed. Ideas and items for News Analysis should be sent to: marita.hefler@menzies.edu.au on worker safety concerns, the Tokyo Metropolitan Assembly passed the Tokyo Passive Smoking Prevention Ordinance.

Under the HPL, in 2019, indoor areas of government offices and other public facilities including universities and hospitals became smoke-free. Controversially, outdoor smoking areas were permitted to continue in the premises of such offices and facilities. On a positive note, many universities have introduced tobacco-free campus policies.

The HPL has wide exemptions for smoke-free requirements in existing restaurants and bars (exempting around $55 \%$ of such businesses entirely). However, the Tokyo ordinance exempts only restaurants and bars without employees. Thus, the ordinance will cover an estimated $84 \%$ of all restaurants and bars and has the potential to be a model for other local governments.

The success of these measures depends on public acceptance. Japanese public awareness of the health effects of SHS exposure, especially for children, has increased. However, there are still widespread misconceptions that restricting smoking to designated rooms or areas, or certain times, is sufficient for health protection. Such misconceptions exist due to long standing, continued advertising campaigns and 'corporate social responsibility' activities by the tobacco industry, as well as government failure to properly warn of the risks of SHS. Banning all tobacco company CSR activities and advertising, together with government education campaigns and improved cigarette pack warnings for SHS health risks are needed for greater public awareness and acceptance.

Another issue of concern is the accommodation under both the HPL and the Tokyo ordinance for heated tobacco products (HTPs), which have gained a large share of the tobacco market in Japan. HTP use will be allowed while eating or drinking in segregated areas, whereas smoking rooms (where permitted) must be used only for smoking. This provision may be ended in the future if the governments accept that HTP emissions are harmful. Currently, relatively few restaurants and bars have chosen to replace smoking with HTP use, but with the enforcement of the HPL and the Tokyo ordinance in April 2020, the number of restaurants and bars adopting the HTP use option may greatly increase. HTPs will not only expose workers and patrons to potentially harmful emissions, but may also undermine the effect smoke free public spaces have of encouraging quitting among existing tobacco users.

While preparation for hosting the Olympics has prompted the introduction of much-overdue legislation, it has also highlighted the continued inadequacy of Japan's approach to tobacco control.

Christopher Rathbone

Smoke Free 2020 Tokyo Olympics, Japan rathbonetrans|@gmail.com

\section{DENMARK: A NEW ERA FOR TOBACCO CONTROL}

Public health in Denmark received an early Christmas present on 18 December 2019, when most political parties agreed on a new tobacco control plan for the country. The plan contains a raft of new measures, including plain packaging of tobacco products, a ban on point of sale advertising, strengthened smoke-free public places including schools and other educational institutions, total ban on smoking by pupils during school hours, and enforced ban on sales of tobacco to persons under the age of 18 . The plan will be implemented as a new tobacco act in 2020 .

The new tobacco control plan followed the passing of the 2020 budget act earlier in December. It included two tax increases in the next twelve months. On 1 April 2020, the price for a pack of twenty cigarettes will rise from 41 to 55 Danish kroner (DKK), and to $60 \mathrm{DKK}$ on 1 January 2021. The overall increase is equal to a rise from approximately 6 to 9 US dollars. Danish authorities estimate the tobacco tax increase and the coming tobacco act will reduce smoking prevalence among young people (aged 25 and below) from $31 \%$ in 2018 to $15 \%$ in 2030.

While these measures are welcome, they are still modest from an international perspective. The projected Danish youth smoking prevalence in 2030 is still five times higher than current youth smoking prevalence in neighbouring Norway. Similarly, the tobacco tax increases are relatively limited compared with those of other high-income countries such as Norway, Iceland, Ireland, the UK, and Australia. These countries adhere to the highest possible prices on tobacco products. In 2020 in these countries, a pack of twenty cigarettes costs the equivalent of 12 US dollars or more.

Such prices have caused a large drop in smoking prevalence, especially among young people. Other countries such as Saudi Arabia, India, Turkmenistan, Malaysia, and Ecuador also have prices 
above 10 US dollars for a pack of twenty cigarettes.

Nonetheless after two turbulent decades in Denmark, the new measures start a new era for tobacco control in the country. In 1998, concerned about a stagnant Danish median life expectancy compared with those of other European countries, the Danish ministry of health made a public health programme for the coming decade. At the time, 13 600 Danes died each year of smokingrelated causes, representing a quarter of all Danish deaths. The public health programme aimed to keep the price of tobacco products in Denmark as high as possible and aimed to reduce smoking prevalence by $1 \%$ per year.

In 2001, Denmark got a new government that weakened the public health programme goals, with the intended aim only to achieve a 'marked' reduction in smoking prevalence. In 2004, the government even reduced taxes on tobacco products. Despite this, until 2014 Danish smoking prevalence continued to fall in line with the earlier public health programme. However, consumption increased gradually from 5.6 billion cigarettes in 2014 to 6.1 billion cigarettes in 2017. Annual surveys in Denmark showed a slight rise in smoking prevalence from $21.1 \%$ in 2016 to $23.1 \%$ in 2017.

During the years from 2015 to 2019, the government announced the 'most ambitious goal for smoking in Denmark', to achieve smoke-free youth by 2030 . Despite the increase in smoking in Denmark after 2014, the government did not pass new legislation for improved tobacco control. One political party in the government, Liberal Alliance, in general opposes increased taxation. So up to the Danish election in June 2019, a central issue in mass media was whether politicians if elected would increase taxation on tobacco products.

The 2019 Danish election gave a new government of Social Democrats led by prime minister Mette Frederiksen. The Liberal Alliance lost half of its representation in the parliament. Later, the parties supporting the new government and two parties of the opposition, Venstre and the conservatives, supported higher taxation of tobacco products and the new tobacco control plan.

For Denmark, currently the economic balance for tobacco is negative. While revenue to the state is approximately one billion US dollars per year, the health costs from smoking-related disorders are approximately two billion US dollars per year. Another estimate including both direct and indirect costs is seven billion US dollars (50 730 million DKK). It is not surprising in the June 2019 election that many Danes voted for higher taxation to reduce the economic gap. The new Danish measures for 2020 and 2021 should stimulate a healthier country, following the role model country Norway.

This article was first published on the Tobacco Control website at https://blogs.bmj.com/tc/2020/01/24/ denmark-a-new-era-for-tobacco-control/.

Finn Edler von Eyben

Centre for Tobacco Control Research, Denmark finn113edler@mail.tele.dk

\section{EUROPE/UK: MENTHOL CIGARETTES \& FLAVOURED TOBACCO BAN}

In 2016, the European Union (EU) announced that the sale and supply of menthol cigarettes and cigarettes with a 'characterising flavour' other than tobacco would be banned by $20^{\text {th }}$ May 2020. The ban includes flavoured rollyour-own tobacco, filters, papers, packages, capsules or other components containing flavourings.
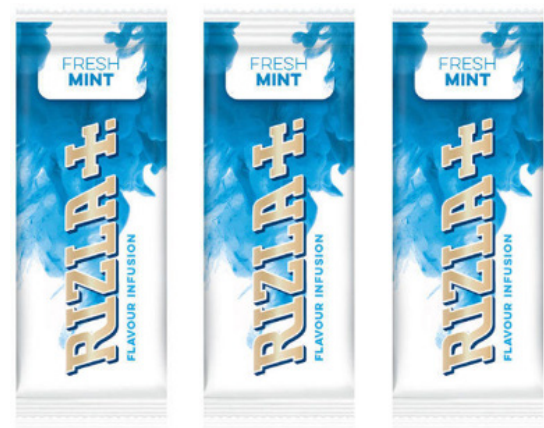

'Flavour infusion' cards sold by imperial brands to circumvent the EU/UK menthol and flavoured tobacco product legislation (2020). Image source: https://static.betterretailing. com/wpcontent/uploads/2019/12/17101354/ menthol-2-768x531.jpg

As there is significant cross-border trade of tobacco products and a risk of diverging national legislation, EU-wide regulations are necessary for tobacco products to protect public health throughout the EU. In 2016, Poland, a large tobacco grower and producer in the EU, attempted to have the ruling overturned; however this was dismissed.

Research indicates that menthol cigarettes may be more attractive to potential smokers, easier to inhale, and may increase the likelihood of children trying cigarettes, while also making smoking more difficult to quit.
According to Eurobarometer statistics, in 2017 menthol cigarettes were used by $8 \%$ of all EU smokers and $11 \%$ of young smokers. Menthol cigarettes are popular in several EU countries, including Finland (used by 24\% of smokers), Denmark (20\%) and the UK (18\%).

Despite the UK leaving the EU in January 2020, it has proceeded with the EU-based legislation. According to figures from the UK Office for National Statistics in July 2018, there were 7.4 million current smokers, with an estimated 1.3 million people in the UK using menthol cigarettes. Market manager for Imperial Brands UK, Chris Street, said "Menthol and crushball sales are collectively worth $26 \%$ of the total UK tobacco market, making up nearly one in four cigarette sales."

Although considerable progress has been made in recent years, smoking prevalence in the EU is still high, with $26 \%$ of the overall population and $29 \%$ of those aged 15 to 24 years reported to be current smokers. Tobacco causes an estimated 700000 deaths annually in the EU alone.

Imperial Brands (formerly Imperial Tobacco Group) was criticised by Action on Smoking and Health UK (ASH UK) for releasing a range of Rizla "Flavour Infusion cards" to circumvent the upcoming ban. The cards are designed to be inserted into a packet of cigarettes or rolling tobacco to produce a menthol flavour ('Menthol Chill' or 'Fresh Mint'), and only cost approximately US\$0.32 cents ( $₫ 0.25 \mathrm{p})$ each. Imperial Brands argues that the cards are "accessories" and are not classified as tobacco products, which the Department of Health (UK) is investigating. Imperial Brands' website states the company “... take(s) pride in behaving responsibly and running our business the right way." As always with tobacco industry rhetoric, the definition of "behaving responsibly" and "running their business the right way" is about profit, not safe products or public health.

The introduction of similar bans on the sale of menthol and other flavoured tobacco products, including filters, papers, packages, capsules or other components containing flavourings is likely to go a long way towards discouraging youth smoking uptake.

John Baker

La Trobe University, Australia J.Baker@latrobe.edu.au 


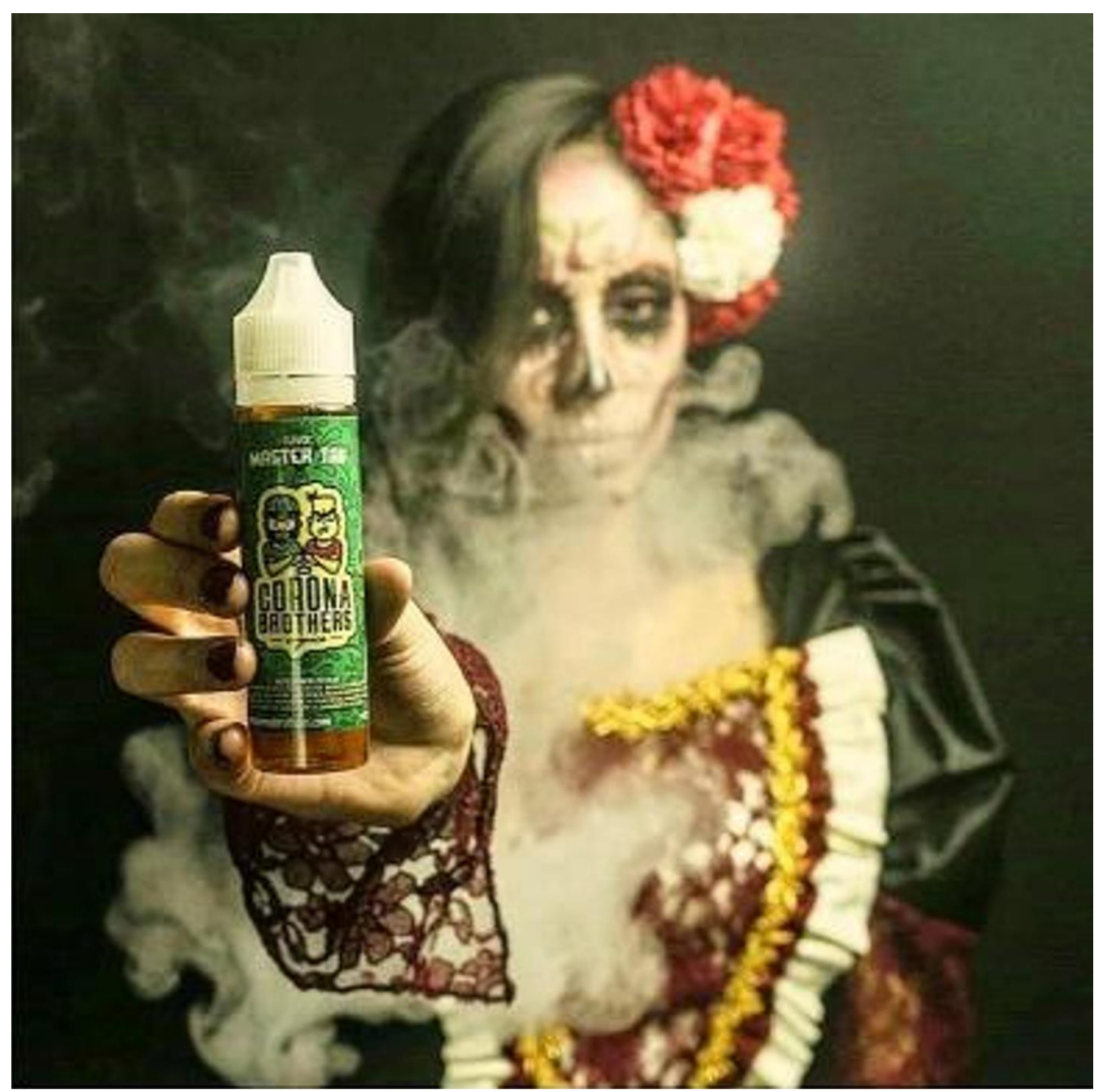

This advertisement found on Instagram shows a model with Catrina-like makeup posing with a vaping device and vaping liquid. The skeleton female La Catrina is known internationally as a figure of the Mexican day of the dead. Image source: https://www.instagram.com/p/ BxfZDC8iCS1/?igshid=kgowk4ln7h2r. Full story: https://blogs.bmj.com/tc/2020/01/20/mexicocultural-icons-and-giveaways-for-vaping-advertising-on-instagram/.

\section{CANADA/USA: JUUL'S TEMPORARY STOP ON FRUIT FLAVOURED PODS}

In January 2020, JUUL announced plans to temporarily stop production of fruit, mango, cucumber and vanilla pods in Canada as part of an ongoing review of the company's practices. However, existing stock in these flavours will continue to be sold in Canada. JUUL's mint, Virginia tobacco and golden tobacco flavours will also continue to be sold on the Canadian market.

Plans to stop the sale of fruit flavoured pods in Canada comes after the U.S announced a ban on all small cartridgebased e-cigarette flavours including fruit, candy, mint and dessert flavours. Menthol and tobacco flavours will continue to be sold while the FDA reviews these products. The FDA stated the new "enforcement priorities are not a 'ban' on flavoured or cartridge-based" pods, but an opportunity to review the products to ensure they are safe for the public and will not be easily accessed by children. The 2019 U.S National Youth Tobacco Survey found more than 5 million youth in middle and high school had used e-cigarettes in the last 30 days, while more than 1 million respondents claimed to be daily users.

In December 2019, the U.S State of Massachusetts introduced a ban on the sale of menthol and other flavoured tobacco products at nearly all tobacco retailers. This includes smokeless tobacco, cigars, pipe tobacco, hookah tobacco, electronic cigarettes and vapour products. The sale of flavoured tobacco products will be allowed at licensed smoking bars, however customers must consume what they buy on-site. The ban will come into effect on first June 2020. Massachusetts has also implemented a temporary ban on the sale of e-cigarette and vaping products until the risks associated with the use of e-cigarette products are better understood.

John Baker

La Trobe University, Australia J.Baker@latrobe.edu.au
BANGLADESH: EDUCATION DIRECTIVE SHOWS BETTER TOBACCO CONTROL NEEDED

Media articles in Bangladesh in early 2020 suggested what at first glance appeared to be a positive development: a tobacco advertising, promotions and sales (TAPS) ban in and around the country's educational institutions. However, a closer look at the announcement revealed problems with enforcement of existing tobacco control measures.

The issue of tobacco advertising and sales around educational institutions has been a focus for tobacco control groups in Bangladesh for several years. The announced ban was merely a directive, issued by the Ministry of Education. While the directive is in line with existing legislation, it potentially undermines existing tobacco control measures, and does not have legal weight.

Bangladesh's tobacco control law, the 'Smoking and Tobacco Products Usage (Control) (Amendment) Act, 2013' prohibits all types of advertisement, promotion, sponsorship of tobacco products. Issuing a new directive covering these issues from the Ministry of Education creates doubt about whether such advertisements and promotions are allowed in other places. Although the intent of the existing tobacco control law is clear, implementation has been extremely weak. Issuing a generalised and vague directive, while not addressing implementation of the existing law, is likely to result in more confusion and less action.

The Department of Education notice also directs authorities of educational institutions and relevant parties to take action against the sale of tobacco products in adjacent areas. This component of the directive is rife with intentional or unintentional lack of precision. A weakness of the current tobacco control law is that there is no provision that bans the sale of tobacco products in areas adjacent to educational institutions. Given the current tobacco control law lacks such provision, it is unclear on what grounds education authorities should implement such a directive. 'Adjacent areas' is not defined, nor is the punishment for violating the directive. The notice for the directive also does not outline mechanisms for implementation, including inter-agency cooperation or resources.

Rather than another directive, full and strong implementation of the existing tobacco control law would thoroughly 


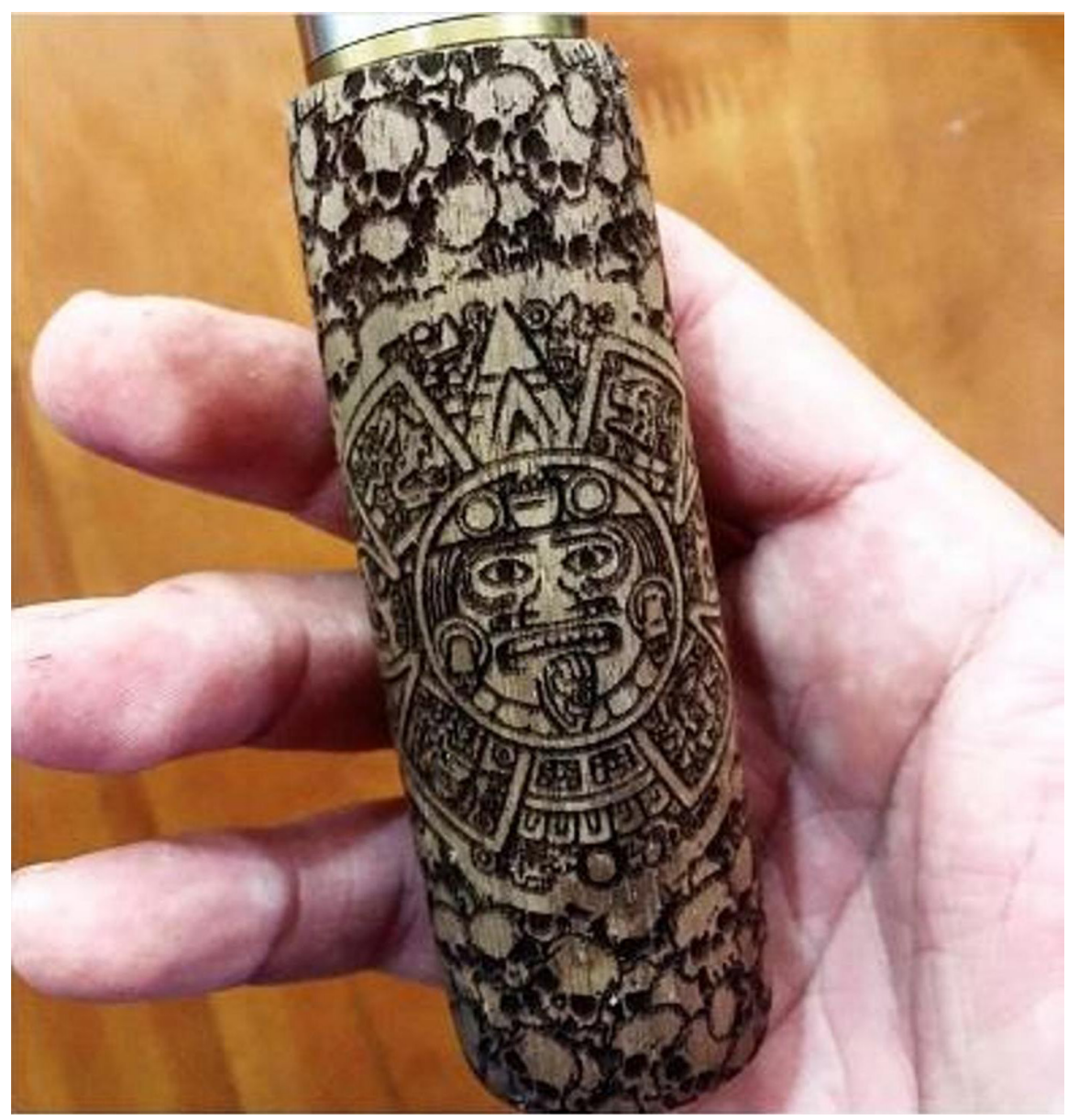

Another Instagram ad using a cultural icon, the Aztec calendar, to advertise vaping on Instagram in Mexico. Image source: https://www.instagram.com/p/Bz0eFa6lwnV/?igshid=1 cj7r8tggimk. Full story: https://blogs.bmj.com/tc/2020/01/20/mexicocultural-icons-and-giveaways-for-vapingadvertising-on-instagram/.

eradicate advertisement and promotion of tobacco products. Such action, rather than another piecemeal approach would be far more effective to reduce smoking uptake among the youth of Bangladesh. It should also be noted that the existing law completely bans smoking in educational institutions. The sale of tobacco products to a minor (below 18 years) is also declared as a punishable offence in of tobacco availability near schools, new provisions should be incorporated into the tobacco control law that ban the radius of educational institutions. said, "the government will also take necessary measures to impose a ban on the sale of tobacco products within 500 metres of educational institutions." The activities of PROGGA and other anti-tobacco organisations have repeatedly prompted policymakers to make such promises and issue sporadic directives. It is time for substantive action consisting of robust and implementation and amending the tobacco control law. Only an amendment of the current tobacco control law can hit the bull's eye. Continued generalised directives with no enforcement mechanisms are bound to fail. The only winner from such an approach is the tobacco industry.

Mahir Dyan Amin

Centre for Research \& Advocacy to Fight Tobacco (CRAFT)

@ PROGGA for Knowledge, Bangladesh progga.bd@gmail.com

\section{FROM THE TOBACCO CONTROL BLOG}

Recent articles published on the Tobacco Control blog outline how the Philippines is pioneering the Tobacco Endgame, against predictable legal challenges from the tobacco industry (https://blogs.bmj. $\mathrm{com} / \mathrm{tc} / 2020 / 01 / 13 /$ the-philippinespioneering-the-tobacco-endgame/), a detailed analysis of Pakistan's need for stronger enforcement of tobacco control measures (https://blogs.bmj.com/tc/ 2019/12/12/pakistan-time-for-strongerenforcement-on-tobacco-control/), and a review of vaping advertising in Mexico using cultural icons and giveaways on Instagram (https://blogs.bmj.com/tc/ 2020/01/20/mexico-cultural-icons-andgiveaways-for-vaping-advertising-oninstagram/). sale of tobacco products within a certain

In 2018, in an event organised by PROGGA, the then-education minister
(C) Author(s) (or their employer(s)) 2020. No commercial re-use. See rights and permissions. Published by BMJ.

D Check for updates

Tob Control 2020;29:127-130.

doi:10.1136/tobaccocontrol-2020-055655 